
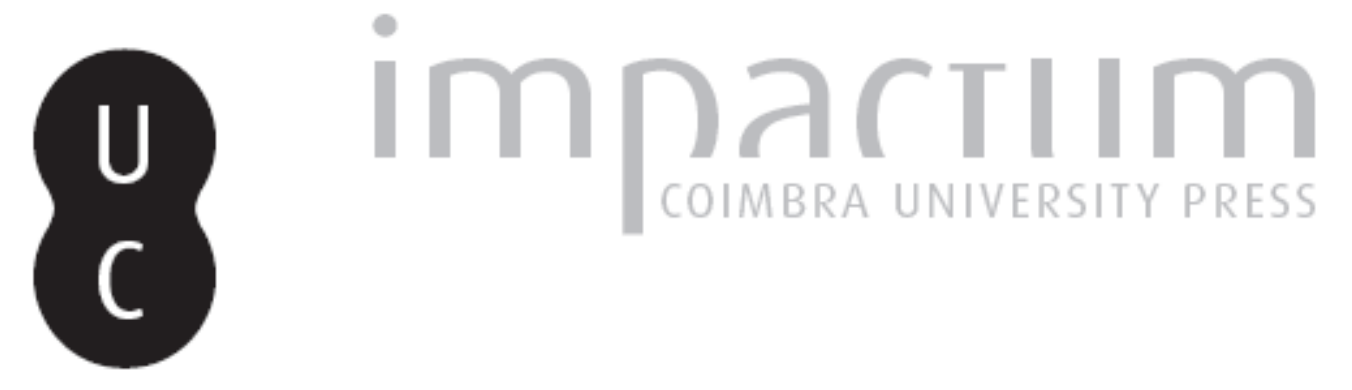

\title{
Antero de Quental e Alberto Sampaio: observadores atentos da história imediata
}

Autor(es): $\quad$ Mendes, José M. Amado

Publicado por: Imprensa da Universidade de Coimbra

URL persistente:

URI:http://hdl.handle.net/10316.2/43749

DOI:

DOI:https://doi.org/10.14195/2183-8925_13_12

Accessed : $\quad$ 26-Apr-2023 09:31:10

A navegação consulta e descarregamento dos títulos inseridos nas Bibliotecas Digitais UC Digitalis, UC Pombalina e UC Impactum, pressupõem a aceitação plena e sem reservas dos Termos e Condições de Uso destas Bibliotecas Digitais, disponíveis em https://digitalis.uc.pt/pt-pt/termos.

Conforme exposto nos referidos Termos e Condições de Uso, o descarregamento de títulos de acesso restrito requer uma licença válida de autorização devendo o utilizador aceder ao(s) documento(s) a partir de um endereço de IP da instituição detentora da supramencionada licença.

Ao utilizador é apenas permitido o descarregamento para uso pessoal, pelo que o emprego do(s) título(s) descarregado(s) para outro fim, designadamente comercial, carece de autorização do respetivo autor ou editor da obra.

Na medida em que todas as obras da UC Digitalis se encontram protegidas pelo Código do Direito de Autor e Direitos Conexos e demais legislação aplicável, toda a cópia, parcial ou total, deste documento, nos casos em que é legalmente admitida, deverá conter ou fazer-se acompanhar por este aviso.

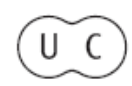


REVISTA DE HISTÓRIA DAS IDEIAS 13

\section{Antero de Quental}

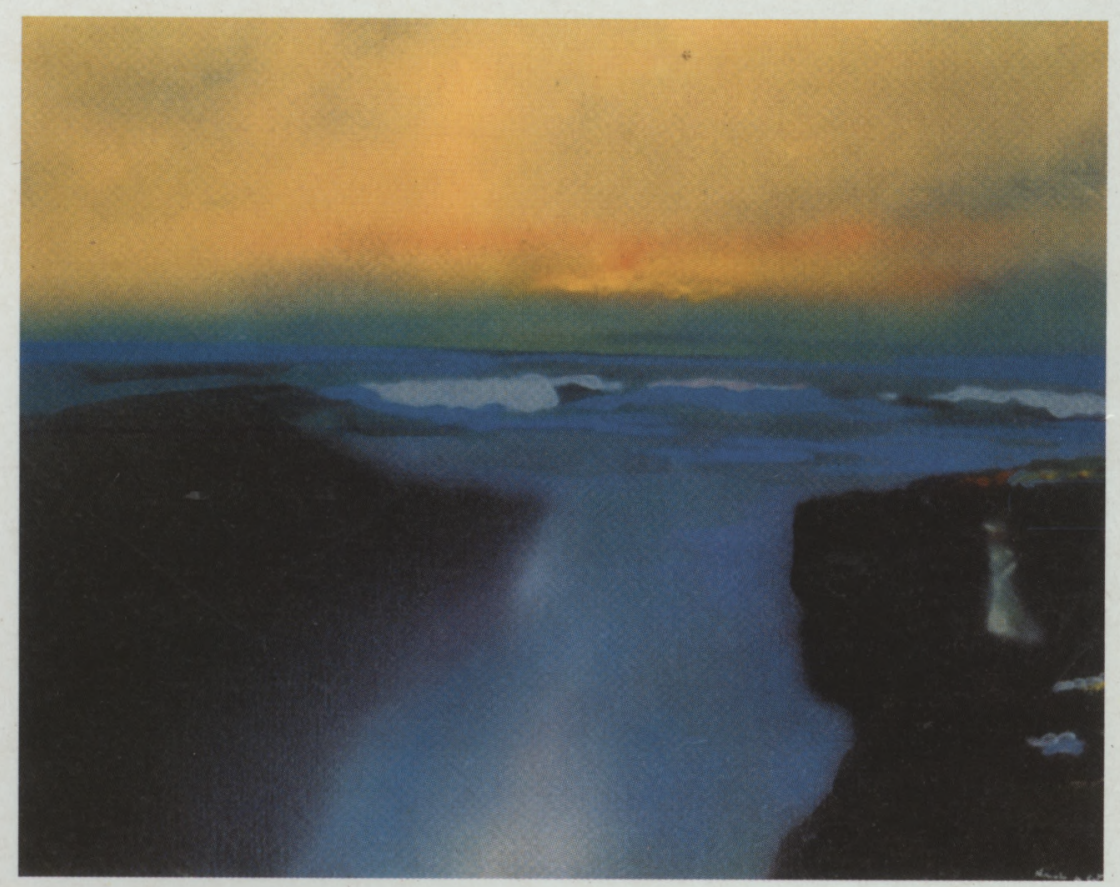

INSTITUTO DE HISTÓRIA E TEORIA DAS IDEIAS FACULDADE DE LETRAS

COIMBRA 1991 


\section{ANTERO DE QUENTAL E ALBERTO SAMPAIO: OBSERVADORES ATENTOS DA HISTÓRIA IMEDIATA **}

\section{Introdução}

Tendo-se completado há dias (11 de Setembro) um século após o falecimento de Antero completando-se proximamente (15 de Novembro) século e meio depois do nascimento de Alberto Sampaio, não surpreenderá que aqui se evoquem as suas memórias e, muito especialmente, as suas obras, perspectivas e eventuais influências recíprocas. Todavia, para além da coincidência cronológica - que, além do mais, constitui ensejo para se aprofundarem os estudos sobre aqueles grandes vultos da nossa cultura -, três outros motivos permitem justificar a associação aqui efectuada, designadamente:

a) a profunda e íntima amizade que entre si cultivaram, desde os tempos universitários de Coimbra (fins dos anos 50 - inícios dos anos 60 de Oitocentos) ( $\left.{ }^{1}\right)$ até à morte de Antero, em 1891;

* Faculdade de Letras da Universidade de Coimbra.

** $O$ texto que ora se publica, devidamente anotado, serviu de base a uma comunicação apresentada ao Congresso Anteriano Internacional, realizado na Universidade dos Açores, em Ponta Delgada, de 14 a 18 de Outubro de 1991.

(') Como sublinhou Luís de Magalhães, Alberto Sampaio foi "condiscípulo, na Universidade, de Antero de Quental, seu fraterno amigo" (Alberto Sampaio, Estudos históricos e económicos, vol. I, Porto, Livraria Chardron, 1923, p. X). Ambos se matricularam, na Faculdade de Direito de Coimbra, em 1858, tendo-se Alberto Sampaio licenciado em 1863 e Antero em 1864 (José Neves Júnior, "SAMPAIO, Alberto(1841-1908", in Joel Serrão(dir.), Dicionário de História de Portugal, vol. III, Lisboa, Iniciativas Editoriais, 1968, p. 731). Os nomes de Anteroe de Alberto Sampaio 
b) a elevada estatura intelectual e moral de ambos, a qual não terá deixado de contribuir para que, na análise de diversas questões do seu tempo, houvesse, muitas vezes, uma nítida coincidência de pontos de vista, sem prejuízo de algumas divergências, explicáveis não só por factores de ordem temperamental, como pela vivência e filosofia - de vida e da história - de cada um;

c) os numerosos testemunhos epistolares que nos ficaram das suas relações e que, em meu entender, não têm merecido, da parte dos estudiosos, a atenção que merecem.

Quanto às relações entre Antero e Sampaio, diferentemente da opinião de Basílio Teles, que as considerou "cordiais mas não íntimas", ${ }^{(2)}$ elas foram efectivamente íntimas, eu diria mesmo "fraternas", como se deduz da análise de diversos factos, para já não aludir ao proprio tratamento "por tu". Em alguns dos momentos mais importantes e cruciais da vida de Antero, este dirigia-se a Alberto Sampaio - seu "confidente", como notou Vitorino Nemésio $\left({ }^{3}\right)$-, solicitando-lhe que lhe desse a sua opinião ou, simplesmente, manifestando-lhe o que pensava, partilhando assim com o historiador da realidade nortenha muitos dos seus problemas, angústias e reflexões. Assim sucedeu aquando da sua dolorosa experiência em Paris, como tipógrafo (1866), $\left({ }^{4}\right)$ ou quando desejou ter a companhia de Alberto Sampaio,

encontram-se entre os dos estudantes que constituíram o núcleo da Sociedade do Raio, entre os quais, de 1858 a 1861, frutificaram laços de amizade e de solidariedade. Cf. António Nóvoa, "A sociedade do Raio na Coimbra Académica de 1861-1863", in Universidade(s). História. Memória. Perspectivas. Actas do Congresso "História da Universidade" (no $7^{\circ}$ Centenário da sua Fundação), 5 a 9 de Março de 1990, vol. 3, Coimbra, Comissão Organizadora do Congresso "Ilistória da Universidade", 1991, p. 284.

(2) Carta de Basílio Teles a Luís de Magalhães, datada de 12.03.1905, publicada por Manuel Villaverde Cabral e Ana Maria Almeida Martins, Uma inesperada amizade política: Basilio Teles e Luís de Magalhães segundo a sua correspondência inédita, 1891-1923, Lisboa, 1991, pp. 81-82. Sep. da Revista da Biblioteca Nacional, série 2, vol. $6(1), 1991$.

( $\left.{ }^{3}\right)$ Notas biográficas sobre Alberto Sampaio, Vila Nova de Famalicão, Câmara Municipal, 1988, p. 26.

(4) Obras completas de Antero de Quental, VI: Cartas, vol. I, [1852]-1881. Organização, introduçãoe notas de Ana Maria Almeida Martins, Lisboa, Universidade dos Açores/Editorial Comunicação, 1989, pp. 85-87 (Doravante referenciá-las-ei apenas por (artas I). À Dr' Ana Maria Almeida Martins, pelas informações dadas sobre a correspondência de Antero e demais colaboração prestada, manifesto a minha sincera gratidão. 
para ambos se alistarem na guarda papal, em Roma (1868), ( $\left.{ }^{5}\right)$ ou ainda quando, anos mais tarde (1884), se preparava para publicar os Sonetos Completos $\left(^{6}\right)$. Mas a profunda amizade que Antero nutria por Alberto Sampaio-ao que este correspondia totalmente e sem reservas-deduz-se ainda das declarações do próprio Antero. Em carta por ele dirigida a Alberto Sampaio, em Janeiro/Fevereiro de 1875, declarava: "Agricultor ou Director de Companhia [Sampaio havia sido convidado para Director da Agência Financeira do Rio de Janeiro, cargo que recusou], és sempre o suave filósofo que eu amo" ( $\left.{ }^{7}\right)$. A amizade entre Antero e Sampaio era reforçada com as visitas daquele a Boamense. A propósito, atente-se no testemunho, de Maria Henriqueta Lino e Sousa, sobrinha de Alberto Sampaio:

"Antero vinha uma vez por ano a Boamense (...) Conta a Tia que o Antero lhe pediu um dia para matar um mosquito que estava numa janela, pois se fosse ele a subir para um banco e fosse para a janela todos diriam: 'lá está o maluco do Antero a matar mosquitos'. Conversava muito e dizia versos. Era um homem muito bonito e muito dado. $\mathrm{Na}$ véspera da ida dele para Boamense, iam-se arranjar os quartos do Tio Alberto e Antero - ainda era a casa antiga - (a casa de Boamense estava a ser restaurada quando o Avô casou) e levar mantimentos. Os dois viviam com um criado que cozinhava, engomava, etc. - eram os únicos três que lá estavam. Almoçavam às 8 horas da noite, jantavam à meia-noite e ceavam de manhã; dormiam de dia e andavam a passear de noite. Diziam que era uma vida muito bonita: nada melhor que ouvir um carro de bois chiar de noite ou ouvir ladrar um cão" (8). Aponta no mesmo sentido o elevado número de cartas que Antero remeteu

(5) Cartas I, pp. 99-100.

(6) Obras completas de Antero de Quental, VII: Cartas, vol. II, 1881-1891, Lisboa, Universidade dos Açores/Editorial Comunicação, 1989, pp. 716-717 (Doravante referenciá-las-ei apenas por Cartas II).

(') Cartas I, p. 268. O facto de ter sido precisamente Alberto Sampaio a abrir o In Memoriam (logo a seguir às páginas de apresentação), o conteúdo do que aí escreveu e as múltiplas referências que faz a Antero, nas suas cartas dirigidas a outros amigos - por exemplo, a Oliveira Martins e a Luís de Magalhães -, comprovam o que se afirma no tex to ) cf. Alberto Sampaio, "Anthero de Quental (Recordações)", in Anthero de Quental. In Memoriam, Porto, Mathieu Lugan, Editor, 1896, pp. 9-29.

( $\left.{ }^{8}\right)$ Citação de um testemunho (dactilografado), existente no espólio de Alberto Sampaio - que se encontra na casa de Boamense, onde viveu o historiador, hoje na posse da família -, do qual a Eng Emília Nóvoa me forneceu, gentilmente, fotocópia. 
a Alberto Sampaio, não obstante a sua "costumada preguiça epistolar", $\left({ }^{9}\right)$ reconhecida pelo próprio Antero e já sublinhada por Ana Maria Almeida Martins $\left({ }^{10}\right)$. Com efeito, das 704 cartas de Antero publicadas, nada menos do que 96 (isto é, cerca de 14\%) destinaram-se a Alberto Sampaio, ( $\left.{ }^{11}\right)$ o que é, de facto, considerável, atendendo ao número diversificado de destinatários.

Consciente da importância das cartas de Antero, Alberto Sampaio informava Luís de Magalhães, em carta datada de 29.06.1892, ou seja, menos de um anos após o óbito do Poeta-Filósofo: "Quanto ás cartas de Anthero, parece-me melhor leval-as eu mesmo: por isso ficam em meu poder. Deste modo evita-se qualquer extravio" $\left({ }^{12}\right)$.

O extraordinário significado das cartas de Antero tem sido, por diversas vezes, sublinhado. Sobre o assunto, escreveu Joaquim de Carvalho, referindo-se essencialmente às dirigidas a Oliveira Martins, mas cujas considerações se aplicam, em grande medida, às destinadas a Alberto Sampaio: "As suas cartas tornam-se assim verdadeiramente páginas de um diário intímo, pela sincera confissão das grandes preocupações morais e intelectuais que lhe agitaram o espírito, e para o crítico, a base mais sólida para o estudo da sua personalidade e das tormentas do seu pensamento" $\left({ }^{13}\right)$. E continua o autor: "Nada lhes falta, desde o informe biográfico ate à vivência dos mais puros sentimentos, desde o transporte $\left({ }^{14}\right)$ das inquietações sociais e políticas de um ser activo, até à perspiććcia do ideal e às agonias lentas de taciturnas meditações solitárias" $\left({ }^{15}\right)$. "Estas cartas - acrescenta, um pouco adiante, o Prof. Joaquim de Carvalho - documentam com exuberante riqueza a evolução espiritual de Antero, desde a fase activa de revolucionário, sedento de justiça social, até à derradeira viragem, em que, enterrado na 'poltrona do filósofo', o pensador, despedindo-se do poeta, demanda e vence as tormentas da vida interior pelo

( ${ }^{9}$ Cartas II, p. 751. Em carta a Oliveira Martins (de Março de 1880).

$\left({ }^{10}\right)$ Cartas I, p. XX.

(") Cartas I e II.

('2) Biblioteca Nacional de Lisboa (BNL), Esp. 2 (de Luís de Magalhães), carta de 29.06.1892.

$\left({ }^{13}\right)$ Joaquim de Carvalho, Evolução espiritual de Antero e outros escritos, Angra do Heroísmo, Antília/Secretaria Regional da Educação e Cultura, 1983, p. 184.

$\left({ }^{14}\right)$ No texto, devido a uma gralha, lê-se "tranporte".

(15) Joaquim de Carvalho, ob. cit., p. 184. 
domínio crescente da reflexão e da consciência. Sob este ponto de vista são singularíssimas no seu epistolário, sendo lícito o vaticínio de que concorrerão para um novo rumo dos estudos anterianos" $\left({ }^{16}\right)$.

Para a considerável relevância das cartas de Antero contribuem ainda outros factores, a saber:

a) Em primeiro lugar, pelo facto de a "sua obra em prosa [ser] praticamente desconhecida, com excepção talvez das Causas da Decadência dos Povos Peninsulares" e, bem assim, a convicção - aliás inexacta - de que Antero "teria deixado uma obra em prosa por demais restrita" $\left({ }^{17}\right)$. "A leitura destas cartas - destaca Ana Maria Almeida Martins, na introdução às Cartas I - vem demonstrar precisamente o contrário porque elas contemplaram os mais diversos destinatários apresentando intenções e objectivos muito variados" $\left({ }^{18}\right)$.

b) Em segundo lugar, devido à extrema exigência e apuradíssima sensibilidade anterianas que levaram o autor a destruir não só alguns dos seus textos manuscritos $\left({ }^{19}\right)$ como a própria correspondência de amigos $\left({ }^{20}\right)$.

c) Por último, face à sua profunda relutância em colaborar na imprensa coeva portuguesa. Assim, dirigindo-se a Joaquim de Araújo, em 13.05.1884, esclarece Antero: "Diga ao seu amigo de Paris que eu sistematicamente não publico - salvo casos de necessidade - uma linha em jornais portugueses" $\left({ }^{21}\right)$. Não ajudará este facto a explicar, pelo menos em parte, as próprias características da correspondência anteriana, a propósito da qual já se aludiu a "apostolado mental e social", a "persuasão particular" e a "persuasão geral" $\left({ }^{22}\right)$, por ela - veiculados? Por outras palavras: não utilizaria Antero a forma epistolar, como outros se serviam da tribuna da imprensa?

A epistolografia tem sido analisada, fundamentalmente, como meio privilegiado para estudos de índole biobibliográfica. Porém, em

$\left({ }^{16}\right)$ Joaquim de Carvalho, ob. cit., pp. 186-187.

$\left({ }^{17}\right)$ Ana Maria Almeida Martins, "Introdução", Cartas I, pp. IX-X.

( ${ }^{18}$ ) Ana Maria Almeida Martins, idem, p. X.

$\left({ }^{19}\right)$ Victor de Sá, Antero de Quental, $2^{2}$ ed., Porto, Limiar, 1977, p. 142.

$\left({ }^{20}\right)$ Mário Cardozo, "A propósito do Centenário de Alberto Sampaio", Revista de Guimarães, vol. LI, n 3,1941 , p. 16, nota 1 .

(21) Cartas II, p. 704.

$\left.{ }^{(22}\right)$ Andrée Rocha, A epistolografia em Portugal, $2^{2}$ ed., Imprensa Nacional-Casa da Moeda, 1985, p. 28. 
certos casos - como os de Antero e Alberto Sampaio -, as suas cartas são igualmente fontes históricas da maior importância. Alguns aspectos específicos, no que se refere às obras/revistas utilizadas - por vezes, através de empréstimo entre si ou entre eles e amigos comuns, como Oliveira Martins -, podem ser estudados pelas cartas que, assim, constituirão um bom complemento aos estudos efectuados com base nas respectivas livrarias $\left({ }^{23}\right)$. Não menos elucidativo será o estudo da história coeva, recorrendo aos testemunhos, esclarecidos e fundamentados, expressos nas próprias cartas. Trata-se, como é sabido, daquela a que, ultimamente, se tem vindo a chamar história imediata ou história do presente, a qual serviu de tema à recente obra de Pierre Chaunu, L'Histoire en cet instant $\left({ }^{24}\right)$. Embora correndo o risco de anacronismo, entendo poder aplicar-se a noção d̀s análises feitas por Antero e Alberto Sampaio à realidade em que estavam inseridos, pela abundante e perspicaz informação histórica que utilizaram.

$\mathrm{Na}$ impossibilidade de focar exaustivamente a problemática acabada de enunciar, analisarei apenas alguns casos, a título de exemplo, privilegiando os de natureza socioeconómica - geralmente menos conhecidos - e a óptica anteriana $\left({ }^{25}\right)$.

\section{Contexto Internacional}

Deixando de parte, por ser suficientemente conhecida, a posição de Antero sobre a Revolução de Espanha (1868) $\left({ }^{26}\right)$ e a Comuna de Paris (1871), foquemos outros eventos.

Numa altura em que os acontecimentos da Comuna de Paris ainda estavam bem frescos na memória, Antero, em carta a Oliveira Martins, elogia o papel revolucionário da França, no contexto mundial, ao invés do que, em seu entender, sucedia com a Alemanha. Sobre o assunto, afirma Antero, em carta dirigida a Oliveira Martins, a 26.08.1874: "A

$\left.{ }^{(23}\right)$ Ver, sobre a livraria de Antero, o trabalho recentemente publicado: Catálogo da Livraria de Antero de Quental, com um Prólogo de Gustavo de Fraga, Ponta Delgada, Biblioteca Pública e Arquivo, 1991.

${ }^{(24)}$ Pierre Chaunu, L'histoire en cet instant, Paris, Ilachette, 1985.

${ }^{25}$ ) A óptica de Alberto Sampaio será por mim analisada posteriormente, em estudos a levar a cabo no âmbito das Comemorações dos 150 anos do seu nascimento.

${ }^{(26)}$ Antero de Quental, Portugal perante a Revolução de Espanha, 1868 (Ver, por exemplo, Antero de Quental, Prosas Sócio-políticas. Publicadas e apresentadas por Joel Serrão, Lisboa, Imprensa Nacional-Casa da Moeda, 1982, pp. 211-241). 
Alemanha, se fizer alguma coisa boa (o que é problemático) será só para si. Mas a França abre as veias para que o mundo todo o [entenda-se 'sangue'] beba" $\left({ }^{27}\right)$. Poucos anos mais tarde (1877), aprecia muito favoravelmente a obra de Balzac: "Os romances de Balzac são uma espécie de história íntima $\left({ }^{28}\right)$ do nosso século, e tenho admirado como em certas coisas capitais (como a influência da bancocracia, a anarquia do livre-câmbio, as ilusões do constitucionalismo, etc.) a sua observação despreocupada da sociedade se encontra e concorda com a crítica sistemática do grande Proudhon. Quando a mim - prossegue Antero -, é este um dos motivos da superioridade de Balzac: enquanto os outros romancistas apenas fazem ideias das paixões humanas, Balzac conhece, além das paixões, os interesses reais, as molas positivas do maquinismo social do nosso tempo. Por isso alguns dos seus livros (como Illusions Perdues) são verdadeiras páginas da história filosófica" $\left({ }^{29}\right)$.

Como que através de uma certa antevisão de alguns eventos que viriam a marcar indelevelmente a história do século $\mathrm{XX}$, nomeadamente os conflitos mundiais e a consolidação de superpotências ou de realidade supranacionais, Antero escrevia, em 1877 (carta a Oliveira Martins, de 17 de Maio): "Neste ponto parece-me que não pode haver duas opiniões. Mas que sairá disto? Uma guerra universal (Rússia e Alemanha dum lado, Inglaterra, França e Áustria do outro) afigura-se hoje como inevitável (...). Considero tudo isto inevitável, entendo que é a crise do século 19, o seu acto final, como o foi para o século XVIII a Revolução Francesa". E volta a interrogar: "Que vai sair desta crise? Duas coisas, desde já, me parecem indicadas: $1^{\circ}$ o desaparecimento das pequenas nacionalidades e formação de grandes aglomerações mais que nacionais, verdadeiros Impérios: $2^{\circ}$ dentro destes Impérios, as questões políticas de que viveu sobretudo o século 19, postas de lado cada vez mais, e cada vez mais as questões sociais e morais (religião, educação, etc.) dominando a opinião e determinando o curso dos acon-

${ }^{(27)}$ Cartas I, p. 256. Já em 1880 se dirigia assim a Oliveira Martins: "Diga-me quem é o tal indivíduo que se encarrega de mandar vir livros de Alemanha, e como ou por intermédio de quem me posso dirigir a ele, para fazer uma encomenda" (Cartas l, p. 494). Ver, sobre o assunto, Carolina Michaëlis de Vasconcellos, "Anthero e a Alemanha", in Anthero de Quental. In Memoriam, pp. 385-425).

${ }^{(28)}$ Hoje chamar-lhe-íamos história da "vida privada".

$\left({ }^{29}\right)$ Cartas I, p. 371. 


\section{Antero de Quental}

tecimentos" $\left({ }^{30}\right)$.

Também Alberto Sampaio, como Antero, estava atento à evolução internacional. Entre muitos outros exemplos - que focarei, com maior desenvolvimento, em trabalho a apresentar proximamente -, atente-se no seguinte, extraído de uma carta escrita por Alberto Sampaio a Luís de Magalhães, em 27.01.1905: "Sem dúvida se há-de ter interessado muito pelas cousas da Russia: não lhe parece que o Czar perdeu a melhor das ocasióes de resolver a questão socialista, pondo-se á frente da revolução? Torna-se certamente o maior potentado do mundo, e deixaria na historia o mais belo exemplo do poder dum homem. Agora não sei o que será! Trevas, luctas de classes, por quanto tempo?" ( $\left.{ }^{31}\right)$. A história da Rússia a partir de então - a Revolução de 1917 e o estalinismo, para já não referir eventos mais recentes, suficientemente conhecidos - como que viria a confirmar e justificar as apreensões de Alberto Sampaio, aquando da revolução russa em 1905.

\section{A(s) Crise(s) em Portugal nas últimas décadas de Oitocentos, à luz da epistolografia}

Nas cartas remetidas por Antero a Alberto Sampaio e a Oliveira Martins, regra geral, e a diversos outros correspondentes, com alguma frequência, a "situação política" era contemplada. De acordo com a teoria decadentista da história pátria, exposta por Antero de Quental nas Causas da decadência dos povos peninsulares $\left({ }^{32}\right)$, partilhada por Alberto Sampaio, Oliveira Martins e outros vultos da Geração de $70\left({ }^{33}\right)$, o diagnóstico era bastante sombrio, embora também se apontando para soluções possíveis.

As críticas, geralmente incisivas, visavam, por exemplo, o Liberalismo, a Regeneração, a questão colonial e a situação económica e financeira, mas também os partidos, inclusive os recém-constituídos entre os quais o Republicano - e, de modo muito especial, a governaçãoeos próprios políticos, seus protagonistas. Vejamos alguns exemplos

\footnotetext{
$\left({ }^{30}\right)$ Cartas I, pp. 375-376.

$\left.{ }^{31}\right)$ BNL, Esp. 2, carta de 27.01.1905.

${ }^{(32}$ Antero de Quental, "Causas da decadência dos povos peninsulares nos últimos três séculos", Antero de Quental, Prosas-políticas, cit., pp. 255-296.

${ }^{(33}$ ) Ver António Manuel Bettencourt Machado Pires, $A$ ideia de decadência na Geração de 70, Ponta Delgada, 1980.
} 


\section{Antero de Quental e Alberto Sampaio}

que ilustram o que se acaba de afirmar.

Sobre a experiência liberal, a seus olhos negativa, interrogava Antero, em carta dirigida a Henrique das Neves (02.02.1883): "Terá este pobre povo, tão enfraquecido moralmente, e intelectualmente desnorteado, por 50 anos de misérias partidárias e de ilusões liberais, e a quem falta um forte sentimento nacional, terá ele capacidade ainda para tantas virtudes?" E acrescentava: "É o que pode ficar duvidoso aos olhos da crítica, instruída pelos exemplos da história: mas não o devemos ao menos afirmar nós, para não desanimarmos de todo e contribuirmos para o desânimo dos outros" $\left({ }^{34}\right)$.

Como se acaba de verificar, não obstante a crítica e o pessimismo patente, Antero não esquece o espírito patriótico, pelo que procura evitar que o desânimo se difunda. Atitude semelhante tomaria mais tarde (1902) o seu amigo Alberto Sampaio, ao colocar na gaveta e ao recusar a publicação de um seu artigo, pelo cepticismo de que enfermava. Escrevia, a propósito, a Luís de Magalhães: "O scepticismo ali é um pecado mortal. A questão devia ser tratada d'outro modo; isto é, expôr as velhas crises mais proeminentes na nossa história e a sua solução, como exemplo de animo para a liquidação da crise actual: do mesmo modo como já se resolveram as difficuldades antigas, se resolverão também as produzidas pelo novo regime da Divida externa" $\left.{ }^{35}\right)$.

A questão colonial africana não podia, obviamente, ser esquecida pelos líderes intelectuais do fim de Oitocertos. O interesse, por todos os problemas significativos do seu tempo, está bem patente na expressão do próprio Antero, ao sublinhar: "Mas homo sum, nihil humanum a me alienum puto" $\left({ }^{36}\right)$.

Alberto Sampaio, por exemplo, equacionava a questão africana em termos essencialmente económicos, ao firmar, em carta a Luís de Magalhães (provavelmente de 1898): "As novidades políticas da sua [carta] são da maior gravidade: a perda total da Africa, ha 40 ou 50 anos atras, pouco ou nada influia na vida da nação; hoje pelo contrario terá consequências desastrosas, pois cessando a exportação de merca-

$\left({ }^{34}\right)$ Cartas II, p. 652.

$\left.{ }^{35}\right)$ Revista de Guimarães, vol. LI, n 3 (Tiragem especial). Correspondência inédita de Alberto Sampaio, 1941, p. 104 (carta de 31.05.1902).

(36) Cartas II, p. 1052. 
dorias, ficarão sem recursos milhares e milhares de pessoas. Com a fome veremos então surgir as maiores complicações sociais". E continua Alberto Sampaio: "Teremos de retrogradar outra vez à $1^{\mathbf{a}}$ dinastia - a sermos uma nação de lavradores? Uma vez que nos falta o talento governativo, isso teria de acontecer: ou provincia de Espanha ou uma nação esquecida num canto obscuro da Europa: mas queiram os fados que não tenhamos de chegar lá através d'um largo período de convulsões sociais" $\left.{ }^{(37}\right)$. Para o autor das Villas do Norte de Portugal, o desenvolvimento industrial, registado no último lustro do século XIX e nos inícios do século XX, estava indissociavelmente ligado, em grande parte, à exportação de produtos industriais para as colónias. Ao invés do que viria a ser considerado, décadas depois, por alguns autores - através da conhecida teoria do "colonialismo não económico" -, Sampaio nãodesligava a questão colonial africana do factor económico, no que se revelava um perspicaz observador.

Para não me alongar demasiado, e deixando por focar vários temas deveras interessantes - o Iberismo, tão caro a Antero, a sua divergência de Oliveira Martins, quanto ao carácter minhoto (O. Martins) ou burguês (Antero) do Setembrismo $\left({ }^{38}\right)$, a crise económico-financeira de 1890-92, a industrialização ou o proteccionismo -, permito-me apenas focar mais três assuntos, reveladores da redobrada atenção e sagacidade com que os autores em foco encaravam a história do (então) presente. Quer Alberto Sampaio quer Antero de Quental, atentos ao papel que, já na altura, desempenhavam os transportes marítimos, sugeriam que se construíssem portos, respectivamente na Região Norte do Continente e em Ponta Delgada $\left({ }^{39}\right)$.

Ainda acerca dos Açores, Antero de Quental, ao mesmo tempo que notava uma certa estagnação social, relativamente ao Continente $\left({ }^{40}\right)$, dava conta de começar a despertar um certo espírito separatista, estimulado pelas dificuldades económicas. Com efeito, em carta a Sebastião Arruda da Costa Botelho (02.09.1890), informava Antero: "Os jornais daqui falam na crise açoriana com cores bem sombrias.

$\left({ }^{37}\right)$ BNL, Esp. 2, Carta a Luís de Magalhães de 30 de Outubro (de 1898?)

(38) Cartas I, pp. 558-559.

$\left({ }^{39}\right)$ "Necessidade de uma doca na Ilha de S. Miguel", Antero de Quental, Obra completa. Prosas da época de Coimbra, Lisboa, Livraria Sá da Costa, 1973, pp.95-100.

$\left({ }^{40}\right)$ Cartas II, p. 1052. 
Vejo porém que se referem especialmente à Terceira e Ilhas de Baixo. Oxalá que em S. Miguel ao menos não vão as coisas tão mal. Dizem os ditos jornais que hános Açores um movimento separatista considerável. Quando aí estive não notei sintoma algum de tal opinião".E acrescenta o autor: "Pertencer a Portugal é com efeito bem triste, mas as Ilhas, para se tornarem e manterem independentes são pequenas de mais, e a unirem-se aos Estados Unidos seria isso a sua completa ruína. Os republicanos daí [Antero encontrava-se então em Vila do Conde] devem considerar isto e verem a questão pelo lado económico, que é essencial" $\left({ }^{41}\right)$.

Já em Ponta Delgada e naquela que foi, muito provavelmente, a sua última carta que escreveu a Alberto Sampaio (de 18.07.1891), Antero voltava a focar a questão, no auge da crise de 1891, após a humilhação do Ultimatum inglês de 1890 e do fracasso do 31 de Janeiro de 1891: "A crise portuguesa começou e irá longe. Só um pensamento nos pode animar no meio das calamidades que nos esperam; é que o último acto do drama que começa será a união peninsular" $\left({ }^{42}\right)$. A propósito do que começava a constar-se, que a Inglaterra, como indemnização, podia lançar mão das Ilhas, Antero sublinha: "Confesso-te que, apesar de tudo, preferiria muito que ficássemos unidos a Portugal, para depois entrarmos, como Estado federal, na União Peninsular. Sabes quão pouco me sinto português; mas ainda me sinto menos inglês ou americano". E acrescenta, pouco depois: "A crise aqui começa também a fazer-se sentir. O monopólio do álcool afecta a produção mais importante da Ilha, que é a batata-doce, de sorte que o descontentamento vai lavrando e com ele o espírito separatista" $\left({ }^{43}\right)$.

Não deixa de ser interessante a função atribuída ao económico, na concepção anteriana de história. De facto, apesar de considerar que a "história é obra de arte; como tal, sujeita ao escrúpulo da forma" $\left({ }^{44}\right)$, Antero não se esquece de apontar, frequentemente, a importância dos factores económicos, no evoluir da história. Ao propor, por vezes, soluções para superar a(s) crise(s), aponta a necessidade de se tomarem medidas administrativas, económicas e políticas. A propósito da
('1) Cartas II, p. 1008.
(42) Cartas II, p. 1058.
$\left({ }^{43}\right)$ Ibidem.
(44) Cartas I, pp. 478-479. 
articulação dos diversos níveis da realidade por Antero, destaca Fernando Catroga: "Em síntese, a política foi pensada (e sentida) por Antero como uma arte dependente das lições da economia e iluminada pelos ditames da moral" $\left({ }^{45}\right)$.

Para concluir, acrescentarei, ainda sobre a filosofia da história de Antero, que ele já se apresentava como um crítico da história erudita - que, posteriormente, viria a ser apelidada de metódica $\left({ }^{46}\right)$-, revelando-se, em contrapartida e de forma coerente, um admirador incondicional da história produzida por Oliveira Martins. Em carta que escreveu ao autor da Teoria do Socialismo, em 29.06.1887, Antero afirmava: "A sua vida nunca mais poderá ser alegre, mas pode ser serena, e uma certa combinação de actividade e de ideal é indispensável a essa serenidade. É evidente que a erudição não lhe poderia dar isso. O ideal da erudição, que bem sabemos que o pode ter, não é talvez para $V$., e em todo o caso não é para o nosso meio. Deixemos pois a Torre do Tombo e mais o seu bolor sapientíssimo" $\left({ }^{47}\right)$.

Como se deduz do que se acaba de expor, Antero de Quental e Alberto Sampaio, embora não coincidissem totalmente quanto aos seus interesses intelectuais - o primeiro foi notável poeta-filosofo, enquanto o segundo foi historiador exímio -, assemelhavam-se num profundo e permanente interesse e empenho pela res publica do seu tempo, a que tenho vindo a chamar, por comodidade da própria expressão, história imediata.

$\left({ }^{45}\right)$ Fernando Catroga, "O problema político em Antero de Quental - U/m confronto com Oliveira Martins", Revista de História das Ideias, vol. III, 1981, p. 509.

$\left({ }^{46}\right)$ Ver José M. Amado Mendes, A história como ciência. Fontes, metodologiae teorização, $2^{2}$ ed., Coimbra Editora, 1989, pp. 68-73.

$\left({ }^{47}\right)$ Cartas II, p. 847. 